\title{
A NON-RANDOMISED, COMPARATIVE CROSS-SECTIONAL STUDY TO ANALYSE THE SIGNIFICANCE OF 'PRESSURE-TO-CORNEA INDEX' IN PSEUDOEXFOLIATION EYES WITH AND WITHOUT CLINICAL GLAUCOMA
}

\author{
Anbazhaghan Amudha1, Essakki Rajeswari², Srinivasan Muralikrishnan ${ }^{3}$, Ponnambalam Arunkumar', Devaraj Manoj5, \\ Bohar Sugapriya ${ }^{6}$, Shanmugam Rajeswari ${ }^{7}$
}

\begin{abstract}
${ }^{1}$ Assistant Professor, Department of Ophthalmology, Madurai Medical College, Madurai. ${ }^{2}$ Assistant Professor, Department of Ophthalmology, Madurai Medical College, Madurai. 3 Junior Resident, Department of Ophthalmology, Madurai Medical College, Madurai. 4Junior Resident, Department of Ophthalmology, Madurai Medical College, Madurai. 5Junior Resident, Department of Ophthalmology, Madurai Medical College, Madurai. 6 Junior Resident, Department of Ophthalmology, Madurai Medical College, Madurai. 7Junior Resident, Department of Ophthalmology, Madurai Medical College, Madurai.
\end{abstract}

\begin{tabular}{l}
\hline ABSTRACT \\
BACKGROUND \\
Pseudoexfoliation syndrome is an age-related systemic disease manifesting itself primarily in the eyes and is characterised by the \\
accumulation of microscopic granular amyloid-like protein fibres. Pseudoexfoliation is the most commonly seen identifiable cause \\
of secondary glaucoma. The significance is that, it has a more aggressive clinical course with higher IOP readings and is difficult to \\
treat due to poor response to medications. \\
Aim- To find out the distribution of PCI in patients with Pseudoexfoliation (PXF) and to find out whether PCI can be taken as a \\
predictor for clinical open angle glaucoma (OAG) secondary to pseudoexfoliation.
\end{tabular}

\section{MATERIALS AND METHODS}

Ours was a non-randomised, cross-sectional observational study conducted over a period of 6 months among 112 eyes of patients above 40 years of age with pseudoexfoliation. The eyes were categorised into the following 4 groups: Group 1- Pseudoexfoliation syndrome; Group 2 - Eyes with pseudoexfoliation with normal corrected IOP but with glaucomatous disc and visual field changes; Group 3 - Eyes with pseudoexfoliation with raised IOP, but with normal disc and visual field; Group 4 - Pseudoexfoliative glaucoma. All the statistical analysis was done using statistical software IBM SPSS Ver. 21.0 (Armonk, NY).

\section{RESULTS}

49 eyes PXS as Group 1, 19 eyes in group 2,16 eyes in group 3 and 28 eyes in Group 4. Kruskal-Wallis test was used to compare the IOP, CCT and PCI measurements between the groups - P value is $<0.001$ which is statistically significant. The mean, SD and range in non-glaucomatous and glaucomatous eyes were compared using Rank sum, Mann-Whitney U test - P value $<0.001$ is statistically significant. This study shows that PCI can differentiate between glaucomatous and non-glaucomatous eyes better than the IOP levels in eyes with Pseudoexfoliation. This can be highly helpful in PXS patients with high PCI, to have a close followup schedule and for early diagnosis and treatment of pseudoexfoliative glaucoma, so that further damage to optic nerve head can be prevented.

\section{CONCLUSION}

Increased PCI values in PXG patients can more accurately indicate the severity of glaucoma.

\section{KEYWORDS}

Pseudoexfoliation Syndrome, Open Angle Glaucoma, Intraocular Pressure.

HOW TO CITE THIS ARTICLE: Amudha A, Rajeswari E, Muralikrishnan S, et al. A non-randomised, comparative cross-sectional study to analyse the significance of 'pressure-to-cornea index' in pseudoexfoliation eyes with and without clinical glaucoma. J. Evolution Med. Dent. Sci. 2018;7(02):233-236, DOI: 10.14260/jemds/2018/52

\section{BACKGROUND}

Pseudoexfoliation syndrome (PXS) is an age-related systemic disease manifesting itself primarily in the eyes and is characterised by the accumulation of microscopic granular

'Financial or Other Competing Interest': None.

Submission 11-11-2017, Peer Review 23-12-2017,

Acceptance 29-12-2017, Published 08-01-2018.

Corresponding Author:

Dr. Essakki Rajeswari,

Assistant Professor of Ophthalmology,

Eye Department OP. No. 50,

Government Rajaji Hospital,

No. 1, Panagal Road,

Madurai-625020. Tamilnadu.

E-mail: eyedrck@gmail.com

DOI: $10.14260 /$ jemds $/ 2018 / 52$

\section{(c) $(1) \ominus$}

amyloid-like protein fibres. Pseudoexfoliation is the most commonly seen identifiable cause of secondary glaucoma. ${ }^{1}$ The significance is that, it has a more aggressive clinical course with higher Intraocular Pressure (IOP) readings and is difficult to treat due to poor response to medications. The IOP measured by the gold standard method, Goldmann Applanation Tonometry (GAT) is based on the assumption that CCT is $520 \mu \mathrm{m} .{ }^{2,3}$ Normal human central corneal thickness (CCT) varies between a range of $490 \mu \mathrm{m}$ to 560 $\mu \mathrm{m} .{ }^{4}$ The IOP becomes falsely high or falsely low on thicker corneas or thinner corneas respectively when measured by GAT. So, IOP has to be adjusted according to the CCT by a correction factor. Since the relationship between CCT and IOP is not linear, 5 there is no standardised formula to recalculate IOP accurately across the prevailing range of corneal thickness and IOP, to be accepted as a universal algorithm, till 
date. So, to overcome this error in correction of IOP by various non-standardised formulae, and also to integrate IOP and CCT as a single risk factor for glaucoma, a new index called as Pressure-To-Cornea Index (PCI) was introduced. ${ }^{6}$ $\mathrm{PCI}$ is the ratio between the highest recordable pretreatment IOP in $\mathrm{mmHg}$ to the CCT in millimetres to the cubic power of three. $\mathrm{PCI}=$ Pretreatment $\mathrm{IOP}$ in $\mathrm{mmHg} /(\mathrm{CCT}$ in $\mathrm{mm})$. Further, corneal thickness in pseudoexfoliation has been found to be variable- either thick or thin. So, CCT remains to be a highly variable factor in case of pseudoexfoliation eyes irrespective of the presence of glaucoma, which in turn will affect the IOP in extreme CCT values. ${ }^{7}$ Even if the correction factor is applied, extreme less or high values of CCT will make the IOP, not comparable and not reliable for treatment and followup of PXF patients. Thus, it can indicate the risk for the development of glaucoma in PXS and act as a predictor for glaucoma and can help us to make the patient to undergo close followup visits, to diagnose early and treat pseudoexfoliative glaucoma better and prevent further damage to optic nerve head. This study attempts to determine the role of PCI in predicting the risk of development of glaucoma in eyes with pseudoexfoliation.

\section{Aims and Objectives}

To find out the distribution of PCI in patients with Pseudoexfoliation (PXF) and to find out whether PCI can be taken as a predictor for clinical open angle glaucoma (OAG) secondary to pseudoexfoliation.

\section{MATERIALS AND METHODS}

Ours was a non-randomised, cross-sectional observational study conducted over a period of 6 months among 112 eyes of patients above 40 years of age with pseudoexfoliation, attending the Outpatient Department of Ophthalmology, Govt. Rajaji Hospital, Madurai. The formula used by our statistician to determine the sample size is $\left[\mathrm{Z}_{1-\alpha / 2^{2}} \mathrm{p}(1-\mathrm{p})\right] / \mathrm{d}^{2}$ where, $\mathrm{Z}_{1}$ $\alpha / 2$ is the standard normal variate at $5 \%$ type I error $(p<0.05)$ which is $1.96, \mathrm{p}$ is the expected proportion in population based on pilot study, is $15 \%$, and $\mathrm{d}$ is the absolute error or precision is $5 \%$. The sample size was found to be 100 . Patients over 40 years of age with pseudoexfoliation, not on any anti-glaucoma medications for more than 15 days nor did undergo any intraocular surgery previously were included in the study. Patients who were under chronic anti-glaucoma medications or had undergone previous intraocular surgery or laser procedures, other secondary causes for glaucoma, angle closure glaucoma, corneal opacities or other ocular pathologies and patients who did not consent for the study were excluded from our analysis.

Data collection was done using a case study proforma by the principal investigator. After obtaining informed consent from all the patients, a detailed evaluation including history, visual acuity, slit lamp examination, gonioscopy (using Zeiss 4 mirror gonioscope), intraocular pressure (by Goldmann applanation tonometer), central corneal thickness by Ultrasound pachymetry (AccuPach), fields and dilated fundus examination were performed. The eyes were categorised into the following 4 groups: Group 1- Pseudoexfoliation syndrome (PXS)- Based on the presence of PXF material over the pupil, lens and angles or anyone these, with normal IOP, normal fields and no optic disc changes; Group 2 - Eyes with pseudoexfoliation with normal corrected IOP but with glaucomatous disc and visual field changes; Group 3 - Eyes with pseudoexfoliation with raised IOP but with normal disc and visual field; Group 4 - Pseudoexfoliative glaucoma (PXG) Eyes diagnosed to have glaucoma secondary to pseudoexfoliation with increased IOP with glaucomatous optic disc changes and field defects.

In those patients with bilateral PXF deposition in the eyes, one eye was selected randomly for evaluation and included in the study. The continuous variables were given with mean (standard deviation) and categorical variables were presented with frequency (percentage). One way ANOVA test ${ }^{\sharp}$ was used for the overall comparison of each parameter such as IOP, CCT and PCI. A post-Hoc test called Tukey's test was used for the pairwise comparison of each parameter. Glaucomatous and non-glaucomatous groups were compared using Two-sample independent ' $t$ ' test. $€ \mathrm{P}$ value $<0.05$ were considered as statistically significant. All the statistical analysis was done using statistical software IBM, SPSS Ver. 21.0 (Armonk, NY).

\section{RESULTS}

Among 112 eyes of patients above 40 years of age with pseudoexfoliation, 49 PXF eyes without glaucoma (PXS) were categorised as Group 1, 19 eyes were included in group 2, 16 eyes in group 3 and 28 eyes in Group 4. The information collected regarding all the selected cases were recorded in a master chart. In our study, all the patients were between 50 to 70 years, of which $41.67 \%$ were between $50-60$ years and $58.33 \%$ between 60 - 70 years of age which shows an increased prevalence with age as noticed in several other studies. There were 58 males and 54 females among the 112 patients with PXF, accounting to $52 \%$ and $48 \%$ respectively. This shows a male preponderance in PXF in our study. Deposition of PXF material was unilateral in 65 patients and bilateral in 47 patients leading to a percentage of $58 \%$ and $42 \%$ respectively in our study. Mean IOP in Groups 1, 2, 3 and 4 were 17.53, 19.63, 25.2 and $28.57 \mathrm{mmHg}$ respectively. Mean CCT in Groups 1, 2, 3 and 4 were $547 \mu$ (SD 11.56), 502 $\mu$ (SD 5.88), 594 $\mu$ (SD 5.57) and 538 $\mu$ (SD 17.78) respectively.

Pressure-to-Cornea Index (PCI) in Group 1 PXS eyes showed a mean value of 116.89 with S.D. 10.24 , in Group 2 showed a mean value of 164.47 with S.D. of 7.22, in Group 3 showed a mean value of 132.25 With S.D. of 7 and in Group 4 showed a mean value of 182.64 with S.D. of 12.4 as shown in Table 1 . As the parameters are normally distributed, a oneway ANOVA test was used to compare the IOP, CCT and PCI measurements between the groups. The obtained $P$ value is $<0.001$ which is statistically significant says that there is a difference in all the above parameters between the 4 groups. The mean, SD and range in non-glaucomatous and glaucomatous eyes were compared using Two-sample independent ' $\mathrm{t}$ ' test. The obtained $\mathrm{P}$ value $<0.001$ is statistically significant, which says that there is a statistical significant difference in the PCI values between Pseudoexfoliation syndrome and Pseudoexfoliation glaucoma: Table 2 . The pair wise comparison between all the 4 groups by Tukey's post-Hoc test showed $\mathrm{p}<0.05$, and all were statistically significant: Table 3. 


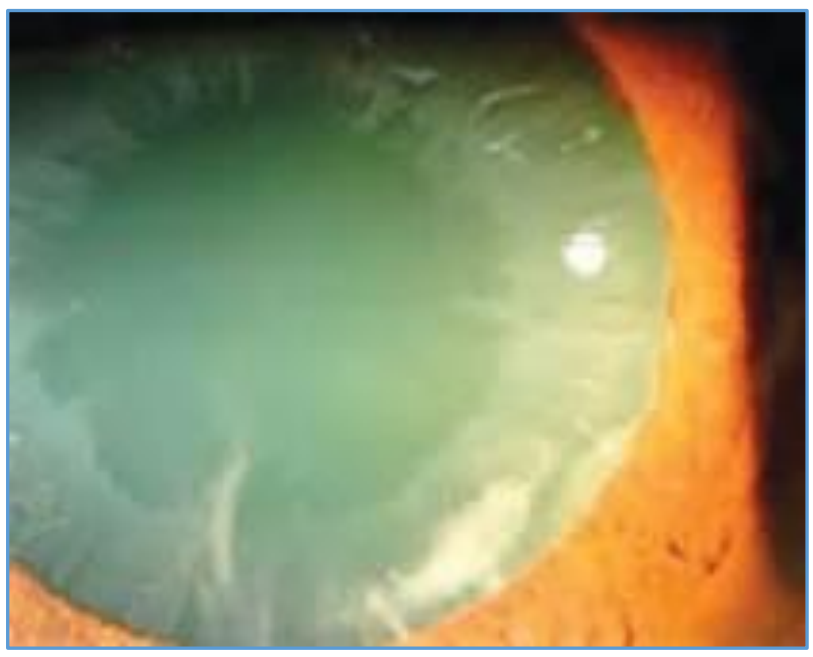

Figure 1: Pseudoexfoliation Syndrome

\begin{tabular}{|c|c|c|c|c|c|c|}
\hline \multicolumn{2}{|c|}{ Parameters } & $\begin{array}{c}\text { Group } 1 \\
(n=49)\end{array}$ & $\begin{array}{c}\text { Group } 2 \\
(n=19)\end{array}$ & $\begin{array}{c}\text { Group } 3 \\
(n=16)\end{array}$ & $\begin{array}{c}\text { Group } 4 \\
(n=28)\end{array}$ & $\begin{array}{c}\mathbf{p} \\
\text { value }^{\ddagger}\end{array}$ \\
\hline \multirow[t]{2}{*}{ IOP } & $\begin{array}{c}\text { Mean } \\
\text { (SD) }\end{array}$ & $\begin{array}{l}17.53 \\
(1.87)\end{array}$ & $\begin{array}{l}19.63 \\
(1.8)\end{array}$ & $\begin{array}{c}25.2 \\
(1.45)\end{array}$ & $\begin{array}{l}28.57 \\
(2.97)\end{array}$ & \multirow[t]{2}{*}{$\mathrm{P}<0.001$} \\
\hline & Range & & & & & \\
\hline \multirow[t]{2}{*}{ CCT } & $\begin{array}{c}\text { Mean } \\
\text { (SD) }\end{array}$ & & $\begin{array}{c}502 \\
(5.88) \\
\end{array}$ & $\begin{array}{c}594 \\
(5.57) \\
\end{array}$ & $\begin{array}{c}538 \\
(17.78) \\
\end{array}$ & \multirow[t]{2}{*}{$\mathrm{P}<0.001$} \\
\hline & Range & & & & $505-567$ & \\
\hline \multirow{2}{*}{ PCI } & & & & $\begin{array}{c}132.25 \\
(7)\end{array}$ & & \multirow{2}{*}{$\mathrm{P}<0.001$} \\
\hline & Range & $92-135$ & \multicolumn{3}{|c|}{\begin{tabular}{|l|l|l|}
$152-178$ & $120-145$ & $160-205$ \\
\end{tabular}} & \\
\hline \multicolumn{7}{|c|}{$\begin{array}{c}\text { Table 1. Comparison of Mean, SD OF IOP, CCT AND } \\
\text { PCI in all the Four Groups }\end{array}$} \\
\hline
\end{tabular}

\begin{tabular}{|c|c|c|c|c|}
\hline GROUP & N & Mean (SD) & Range & P value $€$ \\
\hline $\begin{array}{c}\text { Pseudoexfoliation } \\
\text { syndrome } \\
\text { (Group 1 and 3) }\end{array}$ & 65 & $\begin{array}{c}120.67 \\
(11.6)\end{array}$ & $92-145$ & \\
\hline $\begin{array}{c}\text { Pseudoexfoliation } \\
\text { glaucoma } \\
\text { (Group 2 and 4) }\end{array}$ & 47 & $\begin{array}{c}175.29 \\
(13.85)\end{array}$ & $152-205$ & \\
\hline $\begin{array}{c}\text { Table 2. Comparison of PCI between Non-glaucomatous } \\
\text { and Glaucomatous Group }\end{array}$ \\
\hline
\end{tabular}

\begin{tabular}{|c|c|c|c|}
\hline Pairwise Comparison & $\begin{array}{c}\text { IOP } \\
\text { P value }\end{array}$ & $\begin{array}{c}\text { CCT } \\
\text { P value }^{\square}\end{array}$ & $\begin{array}{c}\text { PCI } \\
\text { P value }\end{array}$ \\
\hline Group 1 Vs. Group 2 & 0.002 & $<0.001$ & $<0.001$ \\
\hline Group 1 Vs. Group 3 & $<0.001$ & $<0.001$ & $<0.001$ \\
\hline Group 1 Vs. Group 4 & $<0.001$ & 0.012 & $<0.001$ \\
\hline Group 2 Vs. Group 3 & $<0.001$ & $<0.001$ & $<0.001$ \\
\hline Group 2 Vs. Group 4 & $<0.001$ & $<0.001$ & $<0.001$ \\
\hline Group 3 Vs. Group 4 & $<0.001$ & $<0.001$ & $<0.001$ \\
\hline \multicolumn{4}{|c|}{$\begin{array}{c}\text { Table 3. Pairwise Comparison of IOP, CCT AND PCI } \\
\text { in all the Four Groups }\end{array}$} \\
\hline
\end{tabular}

\section{DISCUSSION}

Pseudoexfoliation (PXF) was first described by an Ophthalmologist named John Lindberg from Finland in 1917.8 He described it as "grey flakes on the lens capsule". Several decades later, an ocular pathologist Georgiana DvorakTheobald coined the term pseudoexfoliation to distinguish it from a similar ailment which sometimes affected glassblowers called true exfoliation syndrome which is caused by heat or "infrared-related changes in the anterior lens capsule" and is characterised by "lamellar delamination of the lens capsule."9 Its cause is unknown, although there is speculation that there may be a genetic basis (such as mutation of LOXL1 gene). It is little more prevalent in women than men, with outdoor activity, brown cataract and in persons past the age of seventy. Its prevalence varies among different populations, like it is more prevalent in Scandinavia. The buildup of protein clumps over the trabecular meshwork can block the normal drainage of the aqueous humor and can cause a rise in the intraocular pressure leading to glaucoma and loss of vision (PXG). PXF has also been known to cause a weakening of lens zonules leading to lens drop and other complications during cataract surgery. Researchers have noticed deposits of exfoliative material in various parts of the body, including the skin, heart, lungs, liver, kidneys, and elsewhere. As worldwide populations become older because of shifts in demography, PXF may become a matter of greater concern.

This study shows that PCI can differentiate between glaucomatous and non-glaucomatous eyes better than the IOP levels in eyes with PXF. In one study done by Ozcura F et all, there was a significant reduction in CCT in eyes with PXS when compared to the normal eyes but there was no significant difference of CCT between eyes with PXG and the normal population. ${ }^{10}$ While in our study no such significance was seen. PCI is high in cases of glaucoma and low in nonglaucoma cases. PCI can be helpful especially in PXF patients to reduce the errors in IOP across the variable range of CCT values due to non-standardised formulae used. This can be highly helpful in PXS patients with high PCI, to have a close followup schedule and for early diagnosis and treatment of PXG, so that further damage to optic nerve head can be prevented.

\section{CONCLUSION}

Increased PCI values in PXG patients can more accurately indicate the severity of glaucoma and also the response to treatment. High PCI in eyes with PXS without glaucoma can act as a predictor for glaucoma, even before increase in IOP or optic disc/field changes. This shows the individual susceptibility of the person with PXS to development of secondary glaucoma. Hence, PCI can be a useful index for the consulting ophthalmologist to have a close followup and thus for early diagnosis and treatment of PXG, so that further damage to optic nerve head can be prevented.

\section{REFERENCES}

[1] Leske MC, Heijl A, Hussein M, et al. Factors for glaucoma progression and the effect of treatment: the early manifest glaucoma trial. Arch Ophthalmol 2003;121(1):48-56.

[2] Shah S, Chatterjee A, Mathai M, et al. Relationship between corneal thickness and measured intraocular pressure in a general ophthalmology clinic. Ophthalmology 1999;106(11):2154-60.

[3] Matsumoto T, Makino $\mathrm{H}$, Uozato $\mathrm{H}$, et al. The influence of corneal thickness and curvature on the difference between IOP measurements obtained with a non-contact tonometer and those with a Goldmann applanation tonometer. Nippon Ganka Gakkai Zasshi 2000;104(5):317-23.

[4] Thomas R, Korah S, Muliyil J. The role of central corneal thickness in the diagnosis of glaucoma. Indian J Ophthalmol 2000;48(2):107-11. 


\section{Jemds.com}

[5] Ehlers N, Bramsen T, Sperling S. Applanation tonometry and central corneal thickness. Acta Ophthalmol (Copenh) 1975;53(1):34-43.

[6] Iliev ME, Meyenberg A, Buerki E, et al. Novel pressure-to-cornea index in glaucoma. $\mathrm{Br} J$ Ophthalmol 2007;91(10):1364-8.

[7] Ko YC, Liu CJ, Hsu WM. Varying effects of corneal thickness on intraocular pressure measurements with different tonometers. Eye (Lond) 2005;19(3):327-32.

[8] Damji KF. Progress in understanding pseudoexfoliation syndrome and pseudoexfoliationassociated glaucoma. Can J Ophthalmol 2007;42 (5):657-8.

\section{Original Research Article}

[9] Karger RA, Jeng SM, Johnson DH, et al. Estimated incidence of pseudoexfoliation syndrome and pseudoexfoliation glaucoma in Olmsted County, Minnesota. J Glaucoma 2003;12(3):193-7.

[10] Ozcura F, Aydin S, Dayanir V. Central corneal thickness and corneal curvature in pseudoexfoliation syndrome with and without glaucoma. J Glaucoma 2011; 20(7):410-3. 